\title{
MOBILE APPLICATION PENENTUAN JENIS RAWAT PASIEN MENGGUNAKAN METODE SIMPLE ADDITIVE WEIGHTING (SAW)
}

\section{MOCH HASTONO SUMARIANTO}

Teknik Informatika, Fakultas Teknik

Universitas Maarif hasyim latif, Sidoarjo, Indonesia

e-mail:mochtono69@gmail.com

\section{ABSTRAK}

Mobile Application Penentuan Jenis Rawat Pasien Menggunakan Metode Simple Additive Weighting (SAW) sebuah aplikasi yang berfungsi untuk menentukan rawat inap atau rawat jalan menggunakan pehitungan metode SAW dengan 4 variabel yaitu tekanan darah, suhu badan, rawat inap, hasil diagnosa.

Kata kunci : saw, rumah sakit

\section{PENDAHULUAN}

Mobile Application Penentuan Jenis Rawat Pasien Menggunakan Metode Simple Additive Weighting (SAW) sebuah aplikasi yang berfungsi untuk menentukan rawat inap atau rawat jalan menggunakan pehitungan metode SAW dengan 4 variabel yaitu tekanan darah, suhu badan, rawat inap, hasil diagnosa.

\section{METODE PENELITIAN}

Sistem perancangan flowchart, use case diagram, class diagram, squence diagram, activity diagram, perancangan dan desain aplikasi dimulai dengan rancangan detail dari yang sudah disertakan di aplikasi.

\section{Blok diagram}

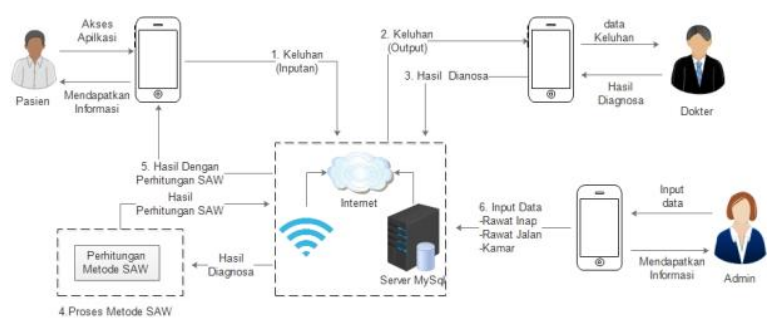

Gambar 1 Blok Diagram Aplikasi

Penjelasan gambar 1 blok diagram adalah sebagai berikut :

1. Pasien memasukan keluhan penyakit yang alami kemudian aplikasi menyimpan data ke mysql server menggunakan koneksi internet

2. Dokter mendapakan informasi keluhan pasien dan mendiagnosa penyakit yang diderita nya

3. Hasil diagnose disimpan ke database mysql menggunakan koneksi internet

4. Setelah hasil diagnose masuk keserver mysql, server akan memproses Perhitungan dengan metode SAW untuk mentukan rawat inap atau jalan pasien tersebut

5. Pasein mendapat hasil diagnose dengan perhitungan SAW

6. Admin menginput data seperti rawat inap, rawat jalan dan data kamar

\section{Flowchart}

Flowchart merupakan bagan-bagan yang mengambarkan alir program. Pada diagram Mobile Application Penentuan Jenis Rawat Pasien Menggunakan Metode Simple Additive Weighting (SAW).

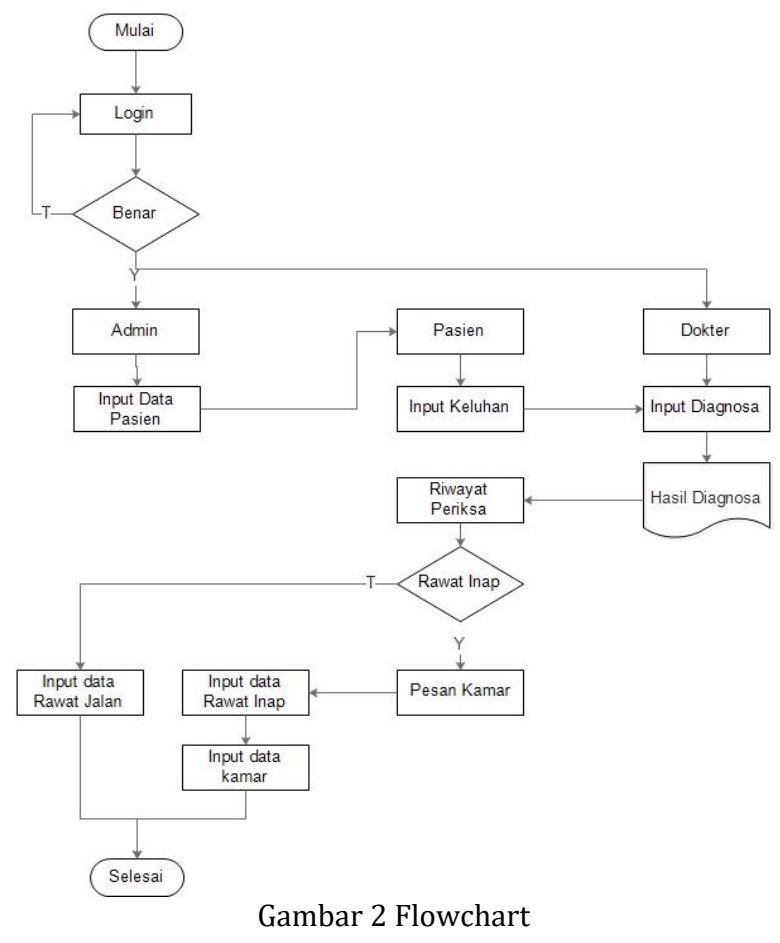

Penjelasan gambar 2 flowchart adalah sebagai berikut :

1. Login dibagi sesuai dengan level seperti pasien, admin, dokter. 
2. Login admin berfungsi input data pasien

3. Login pasien berfungsi untuk memasukan keterangan dan diagnosa pasien

4. Login dokter berfungsi untuk memasukan hasil diaganosa yang diambil dari keluahan pasien

5. Dari hasil diagnose tersebut maka pasien akan menampatkan hasil diagnose dengan penentuan status pasien rawat inap atau jalan

6. Jika pasien ini melakukan rawat inap maka dapat memboking kamar untuk rawat inap.

\section{Use Case Diagram}

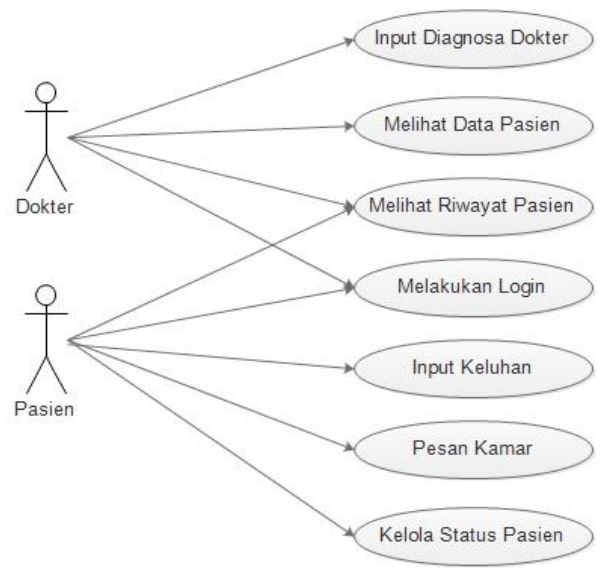

Gambar 3 Use Case Diagram

Penjelasan gambar 3 use case diagram adalah sebagai berikut :

1. Dokter

a) Login berfungsi untuk masuk keaplikasi sesuai dengan level yang dimiliki oleh pengguna

b) Input diasnosa dokter berfungsi untuk memasukan hasil diagnose

c) Melihat data pasien untuk menampilkan informasi data pasien

d) Melihat data riwayat periksa pasien berfungsi untuk melihat data informasi riwayat periksa pasien.

2. Pasien

a) Login berfungsi untuk masuk keaplikasi sesuai dengan level yang dimiliki oleh pengguna

b) Input keluhan berfungsi untuk memasukan keluhan yang dialamai pasien

c) Input pesan kamar berfungsi untuk memboking kamar yang akan digunakan untuk rawat inap

d) Kelola status pasien berfungsi untuk melihat informasi tentang rawat inap atau rawat jalan pasien

\section{Class Diagram}

Class diagram mobile application sistem monitoring pasien rumah sakit berbasis android ditampilkan pada gambar 4. Penjelasan gambar 4 sebagai berikut :
1. Class login berfungsi untuk menampilkan data login aplikasi

2. Class main menu berfungsi untuk merancang tampilan main menu pada aplikasi

3. Class input keluhan berfungsi untuk memasukan input data keluahan pasien

4. Class input diganosa input berfungsi untuk memasukan data diagnose pasien

5. Class data pasien berfungsi untuk memasukan data pasien

6. Class riwayat berfungsi untuk melihta data riwayat pasein
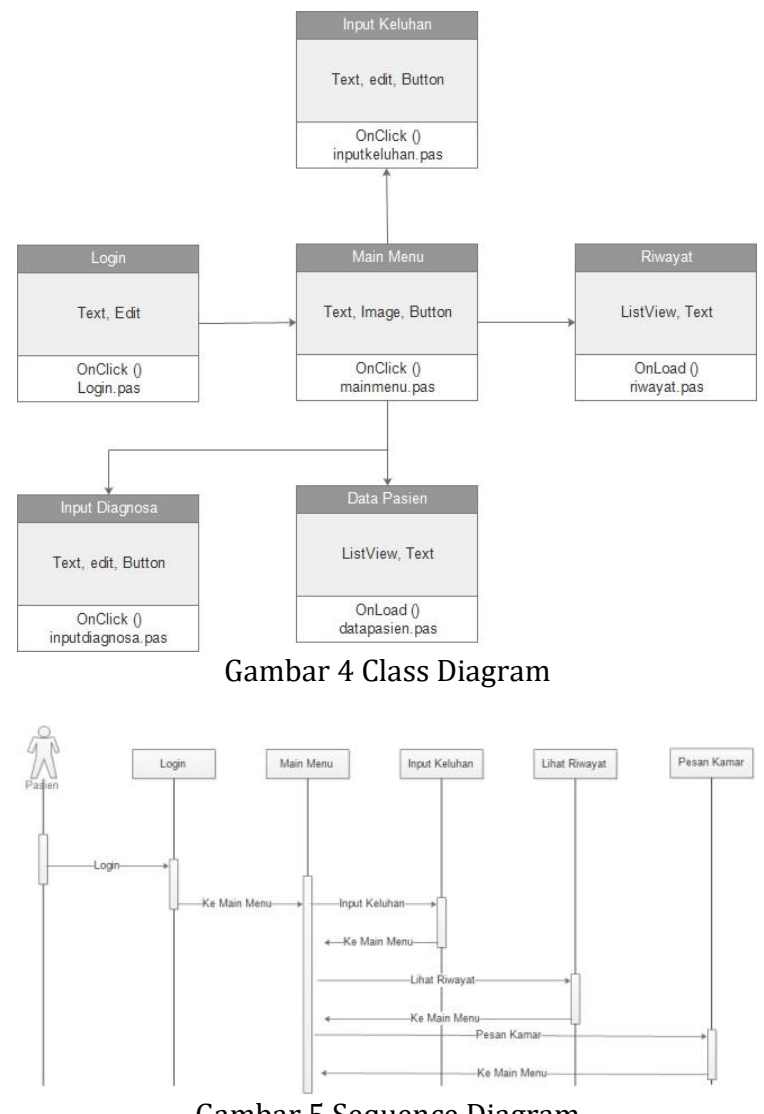

Gambar 5 Sequence Diagram

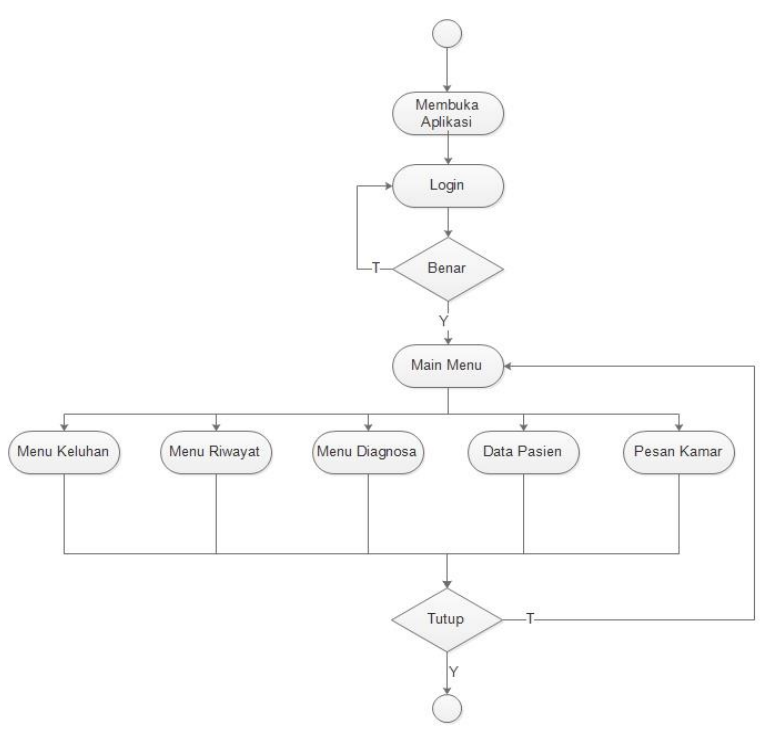

Gambar 6 Activity Diagram 


\section{Sequence Diagram}

Berikut gambar 5 menampilkan Sequence Diagram skenario dan langkah-langkah yang dilakukan application sistem monitoring pasien rumah sakit berbasis android.

\section{Activity Diagram}

Berikut gambar 6 menampilkan Activity diagram yang dilakukan application sistem monitoring pasien rumah sakit berbasis android, Struktur diagram ini juga mirip dengan flowchart.

\section{HASIL PENELITIAN}

Pada penelitian ini akan dijelaskan bahwa yang dikerjakan oleh Pemantauan Kesehatan Pasien Dengan Metode Simple Additive Weighting (SAW) Berbasis Mobile Application Android adalah:

1. Aplikasi Mobile Android Pemantauan Kesehatan Pasien

2. Aplikasi memeliki fitur 2 level login yaitu level login admin dan level login pasien

3. Aplikasi berfungsi untuk menetukan rawat inap atau rawat jalan menggunakan metode SAW.

4. Aplikasi admin memiliki 5 menu yaitu beranda, input hasil diagnose, data pasien, data kamar dan logout.

5. Aplikasi pasien memiliki 3 menu yaitu beranda, riwayat dan logout.

\section{Halaman Login}

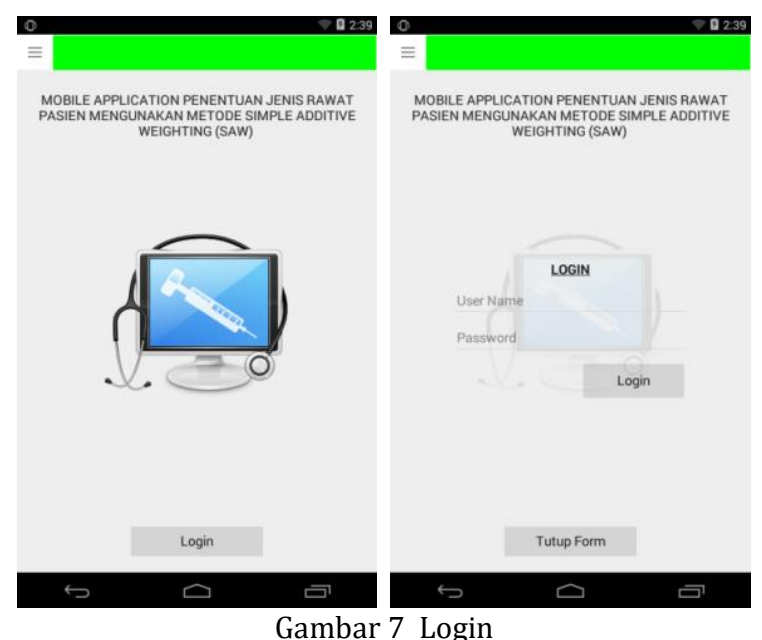

Halaman login berfungsi sebagai pengaman data pada aplikasi aplikasi Pemantauan Kesehatan Pasien Dengan Metode Simple Additive Weighting (SAW).

\section{Menu Admin}

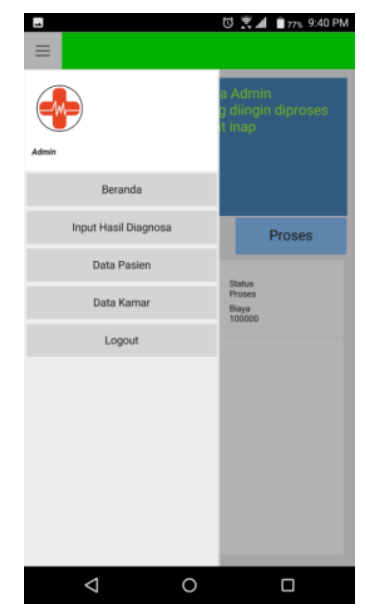

Gambar 8 Menu Admin

Pada aplikasi Pemantauan Kesehatan Pasien Dengan Metode Simple Additive Weighting (SAW) terdapat 5 menu untuk admin yaitu beranda, input hasil diagnose, data pasien, data kamar dan logout yang penjelasannya akan dibahas dibawah ini :

1. Beranda

Menu beranda berfungsi untuk manampilkan informasi tentang pesanan kamar untuk rawat inap yang dilakukan oleh pelanggan, dan untuk memproses pesanan kamar tersebut admin harus memilih data pada listview yang ingin diproses setelah itu pilih proses untuk memproses data tersebut.

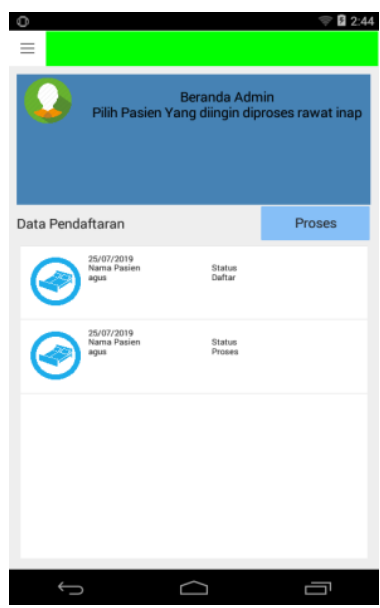

Gambar 9 Beranda Admin

2. Input hasil diagnose.

Input diagnose berfungsi untuk menampilkan form inputan data hasil diganosa yang dilakukan oleh login, data-data yang dimasukan adalah tekanan darah, suhu badan, rawat inap, hasil diagnosa. Ini inputan data ini berfungsi untuk penentuan rawat inap atau rawat jalan pasien. 


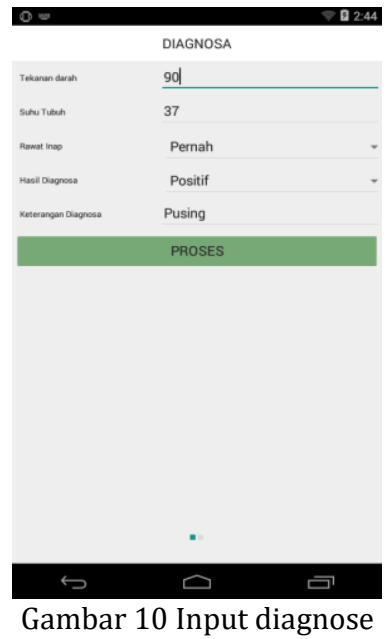

3. Hasil Diganosa

Hasil diagnose berfungsi untuk menampikan informasi penentuan rawat inap dan rawat jalan pasien dengan menggunakan perhitungan SAW

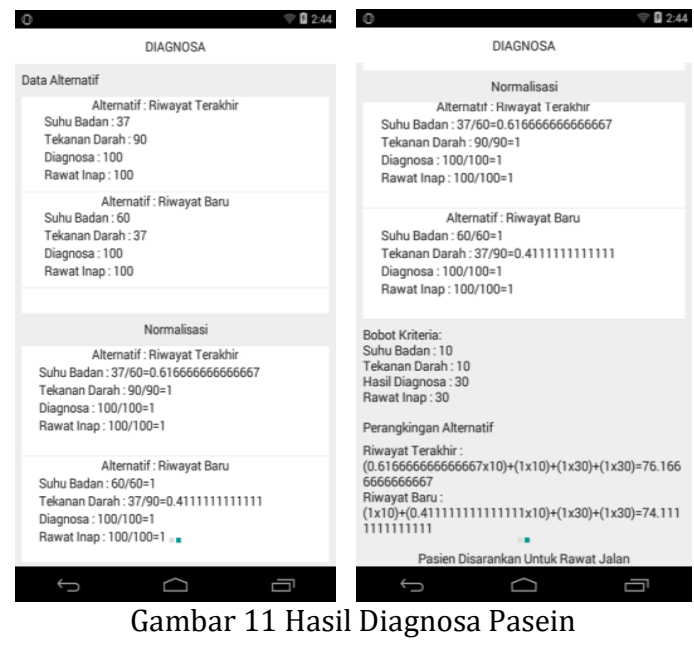

4. Data pasien

Menu data pasien berfungsi menampilkan informasi data pasien dalam bentuk listview dihalaman ini juga disediakan menu tambah, edit dan hapus pasien.

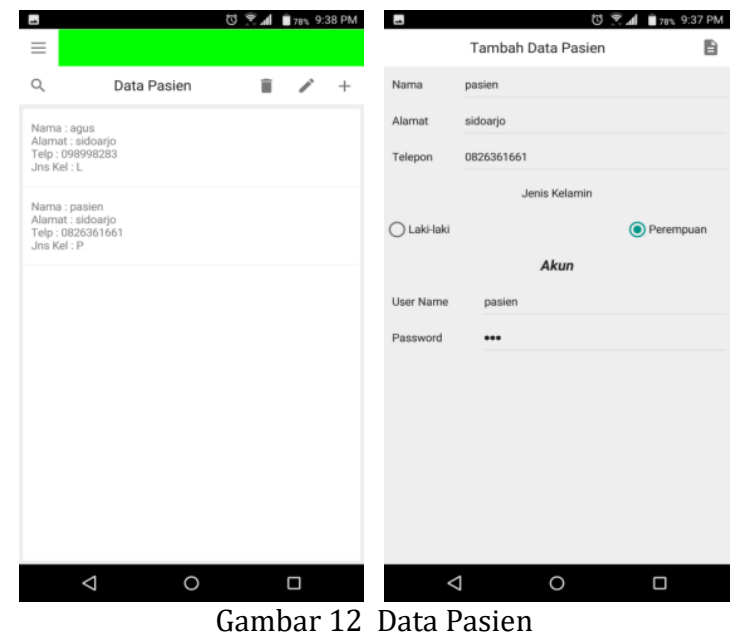

\section{Data Tarif}

Menu data Tarif berfungsi menampilkan informasi data kamar dalam bentuk listview dihalaman ini juga disediakan menu tambah, edit dan hapus Tarif.

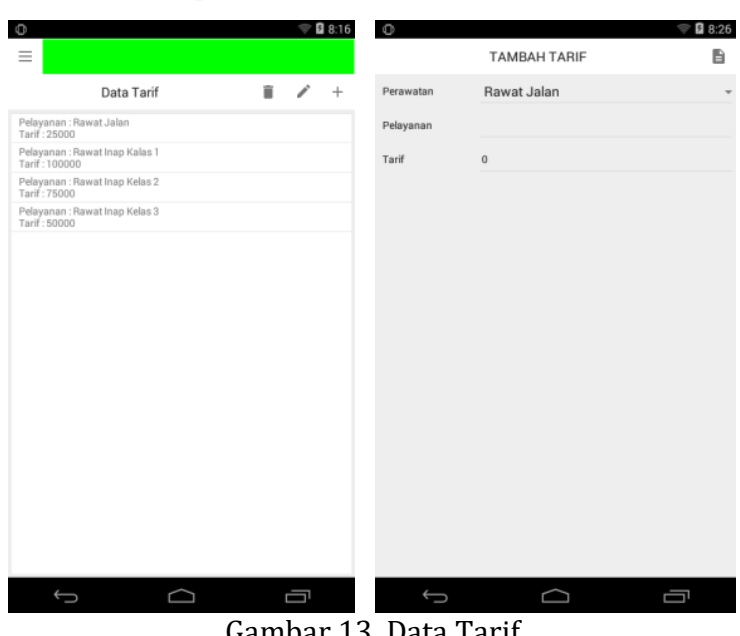

6. Logout

Menu logout berfungsi untuk keluar dari login aplikasi.

\section{Menu Pasien}

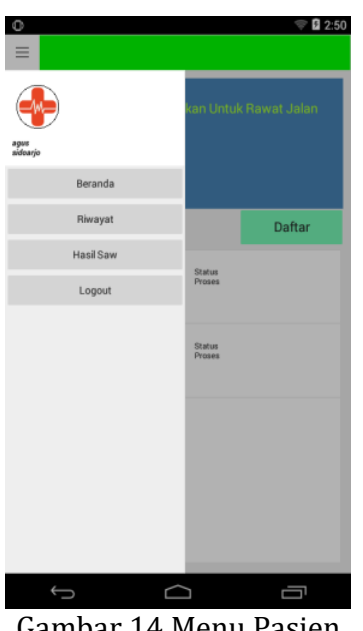

Gambar 14 Menu Pasien

Pada aplikasi Pemantauan Kesehatan Pasien Dengan Metode Simple Additive Weighting (SAW) terdapat 3 menu untuk pasien yaitu beranda, riwayat dan logout yang penjelasannya akan dibahas di bawah ini:

1. Beranda dan pendaftaran

Menu beranda pasien berfungsi untuk menampilkan informasi data daftar rawat inap pasien, dihalaman ini juga bisa melakukan pemesanan kamar yang ingin dipesan oleh pasien tersebut. 


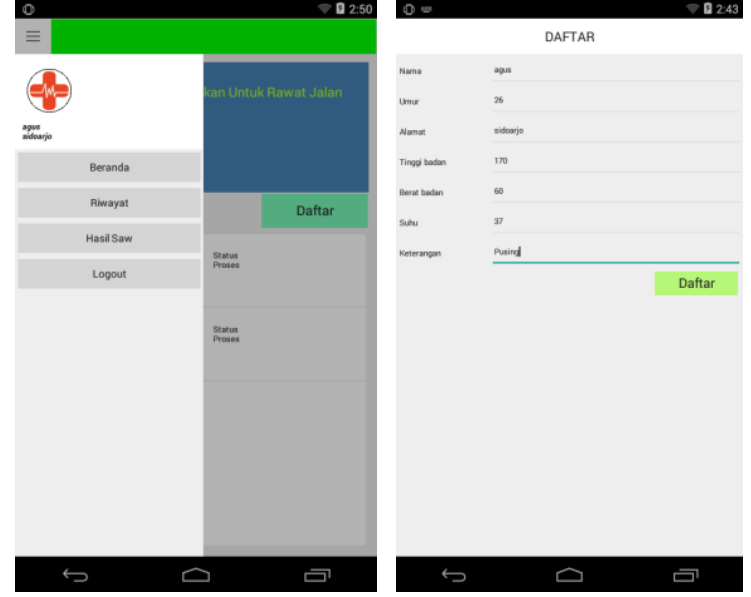

Gambar 15 Beranda Pasien dan pendaftaran

\section{Riwayat}

Menu riwayat berfungsi untuk menampilkan informasi tentang riwayat periksa pasien tersebut, informasi yang ditampilkan dalam bentuk listview.

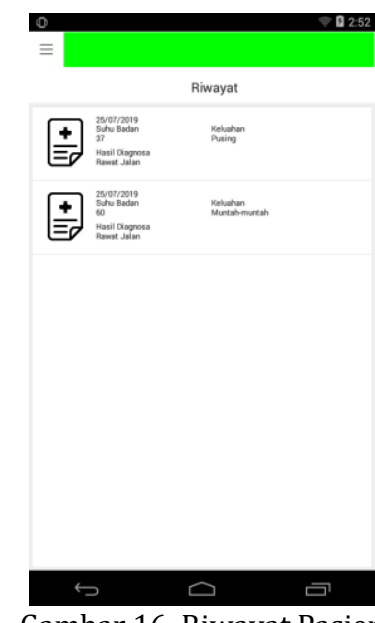

Gambar 16 Riwayat Pasien

3. Hasil SAW

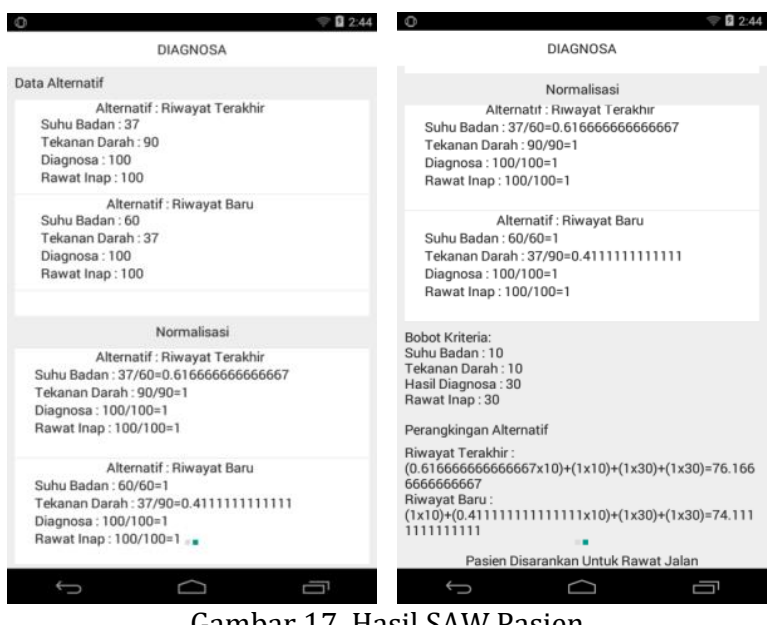

Gambar 17 Hasil SAW Pasien

4. Logout

Menu logout berfungsi untuk keluar dari login aplikasi.

\section{PENUTUP}

Aplikasi mobile ini dapat mengirim data informasi rawat inap atau rawat jalan menggunakan metode SAW. Kecepatan pengiriman data bergantung pada koneksi internet dan Web Service.

Untuk menentukan rawat inap atau rawat jalan menggunakan pehitungan metode SAW dengan 4 variabel yaitu tekanan darah, suhu badan, rawat inap, hasil diagnosa.

\section{DAFTAR PUSTAKA}

[1] I. F. R. Kusumaningati, NGANDROID: Hidup Menjadi Mudah dan Menyenangkan dengan Android. Jakarta: Elex Media Komputindo, 2012.

[2] H. M. Jogiyanto, "Analisis \& Desain: Pendekatan Terstruktur, Teori dan Praktik Aplikasi Bisnis," Yogyakarta Andi, 2005.

[3] Tim EMS, Panduan cepat pemrograman Android. Jakarta: Elex Media Komputindo, 2012.

[4] A. Qiyamullailiy, S. Nandasari, and Y. Amrozi, "Perbandingan Penggunaan Metode SAW dan AHP untuk Sistem Pendukung Keputusan Penerimaan Karyawan Baru," Tek. Eng. Sains J., vol. 4, no. 1, pp. 7-12, 2020.

[5] P. M. Kusumantara, M. Kustyani, and T. Ayu, "Analisis Perbandingan Metode SAW Dan WP Pada Sistem Pendukung Keputusan Pemilihan Wedding Organizer Di Surabaya," Tek. Eng. Sains J., vol. 3, no. 1, pp. 19-24, 2019. 
MH Sumarianto / Ubiquitous: Computers and its Applications Journal, Vol. 3, No. 2, Desember 2020, 77-82 